Revista Mídia e Cotidiano

ISSN: 2178-602X

Editorial

Volume 14, Número 1, jan-abr de 2020

\section{Mídia e infância: perspectivas comunicacionais para a vida cotidiana das crianças}

\section{Media and childhood: communication perspectives for children's daily lives}

\author{
Renata TOMAZ ${ }^{1}$ e Lídia MARÔPO ${ }^{2}$
}

A ideia de fazer o dossiê Mídia e infância: perspectivas comunicacionais para a vida cotidiana das crianças foi impulsionada pelo aniversário do Estatuto da Criança e do Adolescentes que, no dia 13 de julho de 2020, completa 30 anos. O documento oferece garantias que passam necessariamente pelos processos comunicacionais, na medida em que estabelece direitos como o de se expressar e de buscar orientação, além de se divertir e de atuar politicamente. Os 30 artigos submetidos ao dossiê por pesquisadores e pesquisadoras de diferentes partes do país indicaram, entretanto, mais do que motivos legítimos para celebrar. Eles revelaram a inserção de pesquisas produzidas no Brasil em uma área de estudos que está se consolidando no cenário internacional.

Duas das mais importantes instituições de pesquisa em comunicação no mundo confirmaram, na última década, a necessidade de seções específicas voltadas para a relação da mídia com a infância. A divisão temática Children, Adolescents and Media (CAM) foi oficializada pela International Communication Association (ICA), em 2011, e é composta por mais de 200 pesquisadores e pesquisadoras do mundo inteiro. Em 2019, a seção Children, Youth and Media (CYM), fundada pela professora Sonia Livingstone há 3 anos, passou de temporária a permanente na European Communication Research and Education Association (Ecrea). Entre as publicações de maior impacto, voltadas para a

\footnotetext{
${ }^{1}$ Bolsista PNPD/CAPES do Programa de Pós-Graduação Mídia e Cotidiano/UFF. Realizou mestrado e doutorado em Comunicação e Cultura pela ECO/UFRJ. Autora do livro $O$ que você vai ser antes de crescer? Youtubers, infância e celebridade (2019). E-mail: renatactomaz@gmail.com. ORCID: 00000003-1054-7934.

${ }^{2}$ Professora adjunta no Instituto Politécnico de Setúbal e investigadora integrada no Centro Interdisciplinar de Ciências Sociais - Universidade Nova de Lisboa (CICS.NOVA). É doutora em Ciências da Comunicação pela UNL e autora de mais de três dezenas de artigos sobre diversos aspectos da relação entre infância e mídia. E-mail: lidia.maropo@ese.ips.pt. ORCID: 0000-0003-4687-7628.
} 


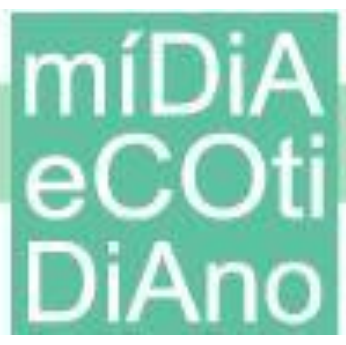

área, está o Journal of Children and Media, da Taylor \& Francis, que publica anualmente quatro edições.

No Brasil, o GT Comunicação, Consumo e Infância encerrou suas atividades em 2014, depois de ficar ativo por quatro anos no Comunicon (ESPM). Apesar disso, é cada vez mais comum a presença de trabalhos sobre mídia e infância em variados GTs de instituições nacionais, como a Intercom e a Compós. Um breve levantamento no Catálogo de Teses e Dissertações da Capes revela um aumento paulatino de trabalhos em torno da temática. Há, nesse sentido, uma demanda por fóruns especializados na comunicação sejam eles em eventos acadêmicos ou em periódicos científicos -, onde a produção desse conhecimento possa avançar para sua institucionalização. A publicação deste dossiê, portanto, tem o mérito de oferecer aos pesquisadores e pesquisadoras do Brasil um espaço que reconhece a interlocução profícua que existe entre a teoria da comunicação e os estudos de infância.

Os textos submetidos tocaram em diversos temas que mobilizam, em um nível global, investigações sobre mídia e infância: sociabilidades no ambiente digital, subjetividades, culturas infantis, relações de gênero, socialização, participação social, representações das crianças, consumo etc. Ao mesmo tempo, o modo como apresentam tais assuntos demonstra, em certa medida, particularidades de uma área ainda em construção no âmbito nacional. A maioria dos textos enviados reservou amplo espaço para a revisão teórica, indicando a necessidade de estabelecer parâmetros conceituais, em detrimento de uma descrição mais detalhada de procedimentos metodológicos e de um maior aprofundamento das análises empíricas que caracterizam a produção científica internacional sobre a temática. Além disso, percebe-se que as referências bibliográficas se restringem, na quase totalidade, a trabalhos publicados no contexto brasileiro, o que sinaliza a ausência de uma maior interseção com estudos realizados em outros países.

Os artigos aqui reunidos representam uma generosa contribuição científica para o campo da comunicação no Brasil e realizam um rico diálogo com as sociedades contemporâneas, ao trazerem discussões que problematizam a presença de meninos e meninas nos espaços midiatizados. A emergência das crianças como figuras produtoras e produtos de práticas sociodiscursivas, na esfera dos processos comunicacionais, afeta as concepções circulantes de infância, forjando novas possibilidades de elas desempenharem 


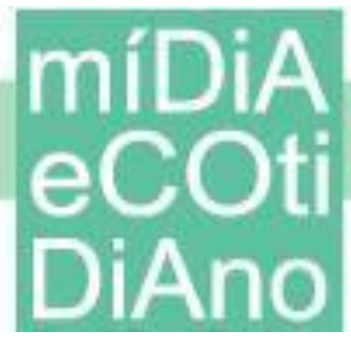

seu papel social ou produzindo-lhes constrangimentos de toda ordem. Comumente afastadas dos tradicionais espaços de poder, as crianças não realizam tal ocupação gratuitamente. Em alguns casos, custa-lhes alto preço, como se vê nos discursos em torno de Greta Thunberg, chamada de "pirralha" pelo presidente Jair Bolsonaro, na véspera de ser eleita, pela revista Time, personalidade do ano de 2019. É sobre ela, a propósito, que versa o primeiro artigo do dossiê.

Em “"Apenas uma garota"”: Greta Thunberg e os enquadramentos da raiva", Henrique Mazetti e João Freire Filho analisam textos informativos e opinativos veiculados na imprensa brasileira sobre a jovem ambientalista. Os discursos de adversários em torno de sua ação política frequentemente evocam a infância como um lugar de incompletude e insinuações implícitas e explícitas sobre gênero e sobre o seu distúrbio de desenvolvimento (Síndrome de Asperger) para desqualificar a atuação da ativista sueca. Por outro lado, perspectivas menos frequentes defendem uma relativa autonomia infantil ou consideram o protagonismo de Thunberg como fruto de uma cultura em que a agência infantil é estimulada. Esses embates discursivos revelam os impeditivos que se impõem para o reconhecimento da participação política dos mais jovens. O modo como a imprensa atua na percepção das crianças como atores sociais é a temática do artigo “'Criança Cidadã?': os manuais de redação e as orientações sobre infância e adolescência", de Thaís Furtado e Juliana Doretto. Ao investigarem os manuais de redação dos jornais de maior tiragem do país, as pesquisadoras buscam entender se as orientações para a cobertura noticiosa, feita por esses veículos, reconhecem as crianças como cidadãs ou se limitam a abordá-las como objeto de cuidados.

Em outros dois artigos, as vozes das crianças são endereçadas para a produção de conhecimento, no ambiente digital. Thinayna Máximo e Inês Sampaio apresentam estudo etnográfico em que investigam o "Uso compartilhado do celular por crianças e familiares: implicações para privacidade on-line e mediação parental", no contexto de um bairro da periferia de Fortaleza (CE). A investigação mostrou que, apesar da partilha dos smartphones com mães e irmãos mais velhos, as crianças encontraram inúmeras estratégias para burlar a vigilância e defender a sua privacidade. Já o artigo "Infância capitalizada nos processos comunicacionais em rede: estudo exploratório sobre o consumo midiático de crianças entre 10 e 12 anos", de Renata Othon e Maria das Graças 


\section{míDiA

Coelho, apresenta diferentes categorias analíticas para investigar o consumo de sites de redes sociais pelos mais novos. As conclusões indicam que as crianças almejam converter o capital social adquirido por meio da sua participação on-line em capital econômico. Demonstram também que os processos de socialização infantil estão profundamente marcados pela perspectiva do consumo e que as crianças definem os meios de comunicação por uma óptica interativa e participativa.

Os três últimos artigos partem de produtos audiovisuais distintos para pensar como suas linguagens atuam na concepção das infâncias e dos modos de ser criança. Em "Youtubers mirins e os vídeos unboxing: uma reflexão sobre a criança conectada nas tramas da publicidade contemporânea", Marcelo Andrade e Gisela Castro problematizam os vídeos unboxing em sua dupla natureza, lúdica e mercadológica. A análise elucidou como a oferta desse conteúdo, por crianças, ao mesmo tempo em que indica produção de subjetividade, permite o estabelecimento da publicidade infantil, a despeito dos mecanismos legais que a cerceiam. Os autores concluem que a junção do entretenimento à publicidade, frequentemente endossada por celebridades mirins do universo on-line, transforma a mensagem comercial em algo relevante, descontraído e capaz de propagar estilos de vida, modos de brincar e ser criança.

O artigo "Definição pela exclusão: apontamentos iniciais sobre os limites conceituais dos programas infantis" toma o conceito de programas infantis como uma categoria de análise para pensar a formação das infâncias contemporâneas, no contexto brasileiro. Ao identificar os elementos que constituem os programas infantis - formatos, linguagem, narrativas, horário de exibição, tipos de protagonistas etc. -, Ariane Holzbach e Wagner Dornelles identificam quais crianças são reconhecidas e quais são excluídas da representação e das audiências destes produtos audiovisuais. Os autores concluem que há uma hegemonia da representação das crianças num padrão europeu moderno e identificam uma relação simbiótica entre os programas infantis e a mercantilização de bens de consumo. Encerrando o dossiê, "Leslie e Ofelia, meninas que ousam sair do quarto: espaço, feminilidade e corpo em Ponte para Terabítia e O labirinto do fauno", Karina Gomes Barbosa se vale da interseção entre estudos da infância e estudos feministas, promovida pelos girlhood studies, para investigar as representações de meninas nos filmes Ponte para Terabítia e $O$ labirinto do fauno. A análise revela o 


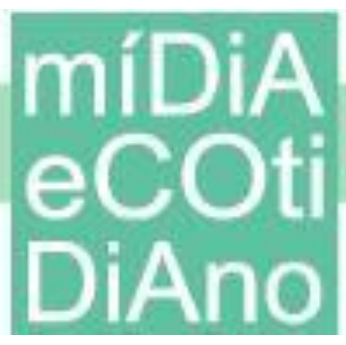

cinema como um dispositivo pedagógico que prescreve modos de ser (ou não) menina, formulando lições para Leslie e Ofelia por ousarem subverter a contenção patriarcal e a feminilidade hegemônica.

Já a Seção Livre desta edição da Revista Mídia e Cotidiano, a primeira de 2020, inicia com o texto "Eu cresci assim: representações de gênero e empoderamento feminino nas telenovelas Gabriela e Tieta", ambas baseadas nas obras homônimas do escritor baiano Jorge Amado e que tiveram um amplo público e até uma segunda versão recentemente, no caso de "Gabriela". Ao focar estas adaptações televisivas, as autoras Valtyennya Campos Pires e Robéria Nádia Araújo Nascimento têm como objetivo discutir as representações de gênero em abordagem que foca não só as protagonistas, mas também as personagens periféricas. Trata-se de uma temática que se coloca hoje como urgente e, também, digamos, incandescente, nas mais variadas possibilidades de interpretação do termo: seja este pensado como iluminador, seja compreendido como capaz de provocar as justas e necessárias discussões sobre as violências e estigmas que embalam as representações femininas na dramaturgia da TV, seja, no mais simples efeito, capaz de tratar de uma temática que vem para romper o largo, escura e sombrio tratamento naturalizado com que se enquadravam estas representações. Em resumo, mais um texto que se agrega a outros da nossa área que tanto têm procurado romper com os silêncios e apagamentos que se constituíram em torno do feminino, particularmente o feminino negro, ao longo desta nossa complexa formação social.

Na sequência e nos mantendo, de certo modo, no território do desvelamento, a Mídia e Cotidiano traz o texto "Os memes como retórica depreciativa nas relações entre Barra das Garças (MT) e Aragarças (GO)”, de autoria de Maria de Fátima Oliveira, Bruna Alves da Silva e Eliezer Cardoso de Oliveira. Falamos em desvelamento porque o artigo, recortando um dos mais férteis campos simbólicos do processo de comunicação atual os memes - traz à tona um caso de relação depreciativa e de ressentimento, que também se vale da lógica do chiste para expressar visões estereotipadas sobre o "outro". A contribuição é particularmente relevante porque assume observar e discutir uma cultura oriunda de pequenas cidades, locais que muitos brasileiros pensam, idealmente, como espaços de cordialidade e de laços comunitários fraternos. Diagnósticos que, pelo exposto no artigo, merecem ser revisados, de modo que tenhamos, quem sabe, uma visão mais 


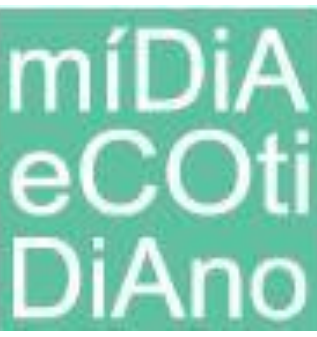

nítida, real e sem ilusões sobre quem somos e como agimos, enquanto brasileiros submetidos e parceiros de uma sociedade construída sob cotidianos hostis e, até mesmo cruéis, a despeito da profunda necessidade que todos temos, uns dos outros, para sobrevivermos.

Mas, para também lembrarmos que nem só de críticas e percepções das nossas dificuldades vivem as pessoas e mídias deste país, o próximo texto, de Paulo Fernando de Carvalho Lopes e Roberto de Araújo Souza traz, provavelmente, uma inversão do nosso olhar, na medida que tem como proposta compartilhar os desafios que envolvem as rádios universitárias. Tais desafios se adensam na medida em que vivenciamos hoje alguns duros reveses em termos de democratização da informação. Isto é, talvez nada seja mais urgente do que essa "reapropriação" dos espaços duramente construídos nestes últimos anos, estabelecendo-se um processo que envolve reflexão, discussão e novas abordagens e soluções: pelo menos é o que parece ser a aposta dos autores. E, finalmente, fechando esta edição o artigo "O movimento antivacina no YouTube nos tempos de pósverdade: Educação em saúde ou desinformação?”, desenvolvido por Bianca Barros da Costa, Daiane de Jesus Viegas, Thamyris Almeida Moreira e Paula Alvarez Abreu, convoca toda a sociedade a não ignorar mais o que está ocorrendo nas mídias sociais em termos de saúde pública, no caso, as campanhas antivacina. Valendo-se de dois levantamentos as autoras mostram com dados objetivos que o ativismo contra vacinação, pelos mais diversos motivos, tem colaborado - muito - para a volta de doenças já erradicadas. Em tempos de assustadores "coronavírus" não é preciso nos estendermos aqui para se compreender a importância desta discussão...

Uma boa leitura a todos!

Renata Tomaz e Lidia Marôpo (Editoras da Seção Temática) Andrea Medrado, Denise Tavares e Isabella Rega (Editoras-chefes) 